\title{
A Comparative Study on the Differences of Chinese and American Business Etiquette Between China and America from Cross-Cultural Aspect
}

\author{
Tingting Xiao ${ }^{1, *}$ \\ ${ }^{1}$ Foreign Languages Department, Jilin Institute of Chemical Technology, Jilin, Jilin 132022, China \\ *Corresponding author.Email: 13106895@qq.com
}

\begin{abstract}
Good manners not only embellish the company image, but also play a major role in generating profit. Nowadays, it is also necessary to apply etiquette to business activities. International trade exchanges have become frequent. People pay more and more attention to good business etiquette quality. As an important link in international business communication, business etiquette plays a crucial role in the smooth development of international business activities. This essay is based on the cross-cultural perspective to study the greeting etiquette, dress etiquette, the concept of time, business card etiquette and so on. By comparing and analyse business etiquette between China and the United States, the excellent cultures of the two countries in business activities can be fully understood, thereby making a reduce on unnecessary friction caused by diverse cultures, and making the cooperation and exchange go on smoothly.
\end{abstract}

Keywords: Business etiquette, Cross-culture, Differences.

\section{INTRODUCTION}

Succeeding in business requires not only mastery of one's job but also mastery of the consideration for others. International exchanges have become frequent. Business etiquette plays a crucial role in the smooth progress of international business activities. Good manners are cost-effective because they not increase the quality of life in the workplace, contribute to optimum employee morale, and embellish the company image. Since China is a large international country, there are more and more international trades. International business communication inevitably happens to the whole process of business activities. Business etiquette is a very critical aspect that nonverbal communication is applied.

As a representative country in the west, the United States has a lot of etiquette to study and learn. At the same time, as the great power in the world, China and the United States have frequent exchanges in both politics and economy. In contact with the United States and other countries, learning more

*Project: Social Science Research Project in Jilin Institute of Chemical Technology. Project No. [2021] 007 about customs, culture, and etiquette can make communication smoothly. The economy can also grow rapidly. You can understand the culture and you can promote the economy.

There are similarities and differences in business etiquette between China and the United States.

We can analyse Chinese business etiquette from the following aspects: first of all, mindset is formation of Chinese way of thinking, which is inseparable from the unique culture of thousands of years. The traditional Chinese mindset is to be friendly and humble. Chinese people are very particular on language expression, which is not direct. Therefore, it is also fully reflected in business contacts. Second, time arrangement is very necessary. For instance arriving at the appointed place in advance shows the respect to each other. Most Americans, compared with the Chinese, always arrive on time when being invited for dinner; no more than 10 minutes later than being invited to a small gathering. If it is a large party, it is acceptable to arrive up to 30 minutes later than invited. The hand shake is the common greeting. Handshakes are firm, brief and confident. Maintain eye contact during the 
greeting. In formal circumstances, you may want to use titles and surnames as a courtesy until you are invited to move to a first name basis. Such as, between men and women, the woman first reaches out her hand. If the woman does not want to shake hands, the man can only nod and bow.

Cross-cultural is a culture that crosses the boundaries between different countries and ethnic groups. Consequently, it is necessary to study crosscultural business etiquette. Business etiquette plays an important role in business activities. More and more business people have realized the importance of understanding diverse business etiquette. However, many business people are not clear to business etiquette. Therefore, the study on differences of business etiquette between China and the United States is of utilitarian significance.

\section{DEFINITION OF CROSS- CULTURAL AND BUSINESS ETIQUETTE}

Different regions have different cultures and different business etiquette. What is cross-cultural? What is business etiquette? Here are the definitions of cross-cultural and business etiquette.

\subsection{Definition of Cross-culture}

Nowadays, culture is often seen as a noun with multiple meanings. The sum of the material and spiritual wealth were created by mankind. In the west, anthropology, the father of the British anthropologist e. b. Taylor, in his "primitive culture" in "the science of culture" chapter, said: "the culture or civilization, in its broad sense of ethnology, is a compound as a whole, including, belief, idea, morals, law, habituate art, and all other abilities and habits acquired by a person as a member of society." Culture is national and world. In fact, cross-culture is a culture that crosses the boundaries between different countries and ethnic groups. It is a cultural difference among different ethnic groups, collective and countries. Individuals have particular cultural identities. Cultural identity refers to the belonging and connection of human groups or individuals to a unique culture. It has an especial worth cultural orientation. The so-called "cross-cultural" refers to the culture that crosses the boundaries between different countries and different nationalities.

For example, a school leader introduced the new American teacher to the others, "Ladies and gentlemen, I'm expected to introduce to you a very pretty gal, Miss Brown. She is a very good teacher, and she came from the USA. But the teachers looked uneasiness. Chinese people like to introduce their guests with complimentary words. But Americans believe that when you meet someone for the first time, you don't have to evaluate them. Any subjective comment, even if it is a good one, will give people a brusque and imposing feeling. For the above remarks, on that occasion, the introduction should highlight the identity, education, position, etc., rather than physical appearance and abstract comments. By contrast, if you change "pretty" and "good" to "tangible educational background and experience," that's a pretty objective statement. Therefore, it is necessary to communicate on the basis of understanding each other's culture to develop empathy and eliminate cultural centrism. The reason why people with different cultural affiliation are not easy to communicate is often due to different understandings of specific cultural phenomena. Only real, fair and comprehensive understanding of heterogeneous culture can eliminate various cultural barriers in the process of cross-cultural communication. On the basis of mastering the culture of this nation, learn as much as possible about the culture of other nations. When Chinese contact with other nations, people can strengthen their own national characteristics and respect the national culture of the world.

\subsection{Definition of Business Etiquette}

Etiquette is a very important way of intercourse. Paying attention to etiquette can improve personal cultivation and promote the success of business activities. Business etiquette is the code of conduct that business workers should observe in their posts. The interpretation of the definition can be understood from the following two aspects. The first is the scope of business etiquette. Just as its name implies, business etiquette refers to the normative behavior in business activities. Therefore, business etiquette is only applicable to trade activities, and it is not suitable to use business etiquette to regulate individual behaviour in daily life and other activities. The second is the object of business etiquette. Since business etiquette only occurs in trade activities, the object of business etiquette is business personnel in business activities, which is also determined by the attributes of business etiquette. According to the interpretation of the definition of business etiquette, there are four elements of business etiquette in commercial activities, including the subject and object of business etiquette, the media and the environment in which business etiquette occurs.

The effects of business etiquette are as follow: 
It coordinates employee relations. Experts are aware of the many advantages of proper business etiquette. In professional situations, extending proper courtesies can help you to make a good impression on colleagues. Moreover, it will make the office environment much more pleasant and will make for better quality work when employees treat each other well. Proper etiquette will also make it more likely that a team of workers will come together to complete a project, which further means that deadlines will be met and employees will feel less burned out.

It creates a good image of employees and companies. Business etiquette is a kind of civilization accumulation of human being. It is also a kind of standard behavior observed by employees. Of course, it can regulate employee's behavior while employees represent the companies they work for. The best intrinsic quality of each employee comes from the continuous penetration of proper etiquette. As it is well knew, good manners make a positive impression. Etiquette, therefore, keeps employees' goodwill as well as maintains the company's image and reputation.

So, learning cross-cultural business etiquette is beneficial to associate with others. It gives us clues as to how to act and what to do in any given situation. Far from stifling your personality in a strait jacket, etiquette by giving you the confidence to handle a wide variety of situations with ease, actually let you focus on being your own, relaxed self [5].

Therefore, the next step is to analyze the characteristics of business etiquette between China and the United States, and make an analysis and comparison.

\section{BUSINESS ETIQUETTE IN CHINA}

Chinese business etiquette has Chinese characteristics and fully demonstrates Chinese culture. Next, there are following expanding aspects.

\subsection{Giving Gift}

China is a nation with a lot of etiquette. With the increasing degree of social openness and international exchanges, business communication with other countries often involves business gift giving. In international exchanges, people often give gifts to express their gratitude and congratulations, so as to promote friendship. Chinese people have a tendency to pay attention to the essence of the gift, that is, its practical value, and do not like what is not useful. In fact, this is mainly because for thousands of years China has been adversely affected by population pressure, lack of resources, and low levels of social productivity. Therefore, more attention should be paid to material life and material practicality. Chinese people not only pay attention to the practical value of gift, but also pay attention to the price tag. When people buy gifts and bestow them abroad, the owner or clerk in a foreign shop often takes the trouble to tears off the price tag, which is exactly what the Chinese want in order to show the real value of the gift. To make the recipient feels sincere and gives such a valuable gift. In order to show their importance, in China, people often accept gifts with a gloomy expression of joy and don't open them in front of the person, which is considered very impolite and gives the impression of being greedy or greedy or overly concerned with the gift. It is usually after the business event or the VIP leaves, or after returning home quietly open the gift. When accepting a gift, Chinese people often refuse to accept it until the other party insists again, which shows that even accepting a gift is out of desperation. Then he set the gift aside, showing indifference. However, the act of quietly opening the gift after the guest has left is proof enough that the Chinese care about receiving the gift, just don't show it in person.

\subsection{Concept of Time}

Einstein said that time is the most precious gift. An old Chinese saying emphasized the value of time. "An inch of time is worth an inch of gold; yet you can't buy an inch of time at an inch of gold." The concept of time from human observers perceives natural movement and the cultural movement of the order. The Chinese are good at observing the cycles of the seasons and observing the cycle of the Yin and Yang [1]. Chinese believe that time is cyclical. And that cycle repeats. Traditional time idea of China, even to the contemporary has an impact. In business activity, the concept of time also fully shows the Chinese people's deep-rooted concept of time. In business etiquette, when Chinese people are working, they make an agreement with their clients to meet and discuss business. No matter whether you have a big chance to win or others are dominant in this negotiation, you might not handle it lightly. Arriving early at the appointed time is not only a sign of respect for others, but also a sign of personal accomplishment and the importance you attach to the job. China, though, has long been accused of being "unpunctual". These days, with the improvement of personal quality and the influence of the west, Chinese people can arrive on time or enter the 
appointed place in advance to wait for the arrival of each other in business activities.

\subsection{Greeting}

In Chinese, greeting is an indispensable form of social communication, no matter whether you are familiar with the other party, you should say "hello". When you meet someone for the first time, smile, look them in the eye, lean forward, and shake hands. When people greet you, you should be polite to the other party. Sincere tone and generous attitude are more likely to win the goodwill of others. If two people are of the opposite sex, the woman should hold out her hand first and the man should shake it back. Chinese greetings in business contacts are very reserved. Just like the Chinese character, it is reserved, considerate and always begins with some daily greetings. For example, "How are you?", "Did you have breakfast?" This is not only conducive to close the distance with customers, promote the success of business negotiations, but also conducive to reflect their own quality and moral character. Business contacts are also very exquisite. First of all, different greetings can be used at different times. Besides the common "hello", greetings can also be changed according to time, people and place. Before 10 a.m., you can say "good morning", from 12 to 14 a.m., you can say "good afternoon", from 18 to 21 p.m. you can say "good evening". After 21 o'clock, if there is no urgent matter, do not call the other party again, so as not to affect other people's rest. Second, greet by announcing your name. Your name should be announced as soon as you say "hello" on the phone. If you continue talking about business, the other person will not be able to respond immediately. This can cause trouble for the other party. The person may be embarrassed to ask, "Who are you?" Because if you can't hear the voice of someone you know very well, it can also make the person who answers the phone uncomfortable. Especially the superior calls the subordinate, must announce the name first. Finally, greetings to pay attention to the tone, tone. On the phone, neither party can see the other's expression, and the only way to communicate is through hearing [4]. Therefore, when greeting the first to tone appropriate, moderate tone, clear articulation, not to say dialect. Greetings that are too slow, too loud, or too weak can make the other person feel bad, which can affect the outcome of a phone conversation.

\section{BUSINESS ETIQUETTE IN AMERICA}

American business etiquette can fully reflect the native culture of the United States, from the following three aspects of detailed analysis.

\subsection{Greeting}

When Americans meet their guests, they usually shake hands. They used to hold hands tightly, eyes to look at each other, slightly hunched. That's considered good manners. Americans have an aversion to look the other person in the eye when shaking hands. This is considered arrogant and impolite [3]. When shaking hands with a guest in a social setting, Americans also have some other customs and rules. If it is of the same sex, the older person should usually extend his hand to the younger person. The senior person should extend his hand to the junior person, and the host should extend his hand to the guest. Their other courtesy is kissing. This is a courtesy shows that they are very familiar with each other. Kissing ceremony, often accompanied by a certain degree of hug, different relationships, different identities of people, the kissing parts are each other's are not the same. In public and social occasions, close women can kiss each other on the face, men hug each other, and men and women usually kiss each other the cheek. Juniors kiss their elders on the forehead; a man may kiss the finger or the back of his hand to a distinguished female guest. Americans also have three major taboos: the first is to avoid someone asks his age. The second is to avoid asking him the price of things. The third is to avoid meeting and say: "You put on weight! Because age and price are personal matters, they don't like interference. As for "You're putting on weight!", this is a Chinese custom of "praising". In the United States, this behavior is derogatory. Americans address each other by their first names. They usually do not address each other by "Mr", "Mrs", "miss" or other titles. Try to get your point more quickly.

\subsection{Concept of Time}

In general, Americans do not evaluate their visitors through long chats in a casual atmosphere; nor will a restaurant invite guests to establish a sense of trust and friendship before the business is settled. For most, friendly relationships are not as important as actual performance. They focus on past track records rather than social etiquette to evaluate a peer. They typically evaluate and discuss things from a professional perspective rather than a social one, so 
they quickly get down to business. Most Americans fill their schedules with appointments and divide their time into sections [6]. These schedules can be separated by periods as short as 15 minutes. They often "Give"; two or three (or more) time slots per person. In business, however, it's almost always date after date, no matter what they're doing. As a result, the ticking of the clock was always in their ears. Americans believe that time can be arranged, saved, wasted, encroached upon, killed, etc. They also charge for their time, because they believe that it is a valuable resource and a precious commodity. In fact, Americans do not spend much time chatting with visitors or entertaining guests in restaurants to establish friendly and cooperative relations. So, after a brief, polite greeting with the guest, they quickly got down to business. Due to Americans regard the time as one part of his life. They hate people who waste other people's time unwisely. If they feel that time is slipping away and they have nothing to gain, they start fidgeting and getting emotional. Americans like to do work by planned, so they do everything according to a strict schedule. If they find themselves behind schedule, they squirm and try to speed up [2]. When Americans did a plan for some event, they usually advanced the time by days or weeks. After the time is determined, it is not easy to change unless the situation is urgent. All meetings, appointments, social events, etc., need prior notice so that the other party can make early arrangements. It considers impolite to inform the other party of an event.

\subsection{Characteristics of Clothing}

We pay attention to dressing in formal social occasions. There is a dress code at the banquet. There are about five types of dress codes in the United States: formal (semi-formal), informal (business attire), business casual, casual, and sportswear. If you're invited to a party, the first thing you shouldn't be rush to find the right dress, but ask for the party's dress code. When attending an important meeting, you should pay attention to the dress code on the invitation. If you are not sure about the clothing requirements, you can ask other participants first to avoid embarrassment. The bottom button of the vest is usually unbuttoned. On formal occasions or at work, women should wear skirts, while men should wear ties and dark suits. An evening dress should have an ankle-length hemline and high heels. At present, Tuxedo and Lounge suite Tuxedo, which are widely used in business activities, are mainly utilized in banquet activities. Tuxedo is characterized by cleanliness. The collar is trimmed with smooth, shiny satin, a wide, smooth ribbon or silk belt, and a black bow tie, with only one buckle at the waist; lounge suite, on the other hand, is actually a dark suit, which requires the same texture and style of upper and lower. This not only reflects the respect for the activities but also reflects their own taste. Moreover, it is considered impolite to wear pajamas, slippers or go out in this dress. Americans believe that wearing make-up in public, or in front of a large crowd, is not only considered ill-bred. It can also make people feel suspicious. Generally speaking, Americans are not particular about what they wear at the ordinary time. They advocate nature, prefer looseness, and pay attention to dressing to reflect personality, which is one of the basic characteristics of Americans.

\section{THE DIFFERENCES OF BUSINESS ETIQUETTE BETWEEN CHINA AND AMERICA}

Based on the analysis of American and Chinese business etiquette in the first and second sections, it will make a comparative analysis of Chinese and American business etiquette in different aspects.

\subsection{Talking}

In business contacts, there is a high demand for business eloquence. Talking is an art. Americans may not be able to accept Chinese people's humor. And the American jokes are not always understood by the Chinese. In business activities, know the enemy and know yourself, and you can fight a hundred battles with no danger of defeat. First, American communication are more private when they talk. In China, however, the boundaries of personal privacy are far less profound, and people do not care about others' general understanding of their lives. Second, Americans seldom use modest words. Americans are direct. They value logic and linear thinking and expect people to speak clearly and in a straightforward manner. To them if you don't say it directly, you simply waste time, and time is money. However, Chinese often use modest words. For example, when receiving a compliment, the Chinese will euphemistically say "It's no big deal" instead of accepting it cheerfully. Americans seldom use exchange of conventional greetings. They pay little attention to greetings in business meetings and pay much attention to efficiency. Chinese people are more accustomed to the use of enthusiastic language. When meeting business partners to visit, it will be very warm and hospitable. In fact, talking is an art. 


\subsection{Table Manners}

Shakespeare said that the most appetizing thing at a banquet was the host's courtesy. Although business dinners take different forms, what they all have in common is a measure of sociability over and above that of an office-bound appointment. Your good manners at business parties will help you to cultivate friendship with your clients. In fact, the Chinese people eat more casually than the Western ones, although there are more and more rules concerning with other guests. Tables in China are usually round. Seat facing the door is for the host. And main guests just sit side by side. So it's cosy to talk. While Americans like a quiet and natural environment when they have dinner, they think that they must pay attention to their appearance at the table and not lose their manners. For example, dishes should not collide with each other when eating, and food should not make noise. The difference is that everyone in the United States to the right is for the respect, gentlemen and ladies are separated and sit, and couples not sitting together. The seats of the female guests are slightly higher than the male guests; men should be placed on his right for the female guests to pull the chair, to show respect to the woman. Besides that, when eating, everyone in the United States is to sit straight, thinking that bending over, or bowing, with the mouth up to eat, is not polite. And the host does not advocate heavy drinking during the meal. Drinks play an important role in Chinese food culture. Usually, both alcoholic drink and beverage are served throughout the meal. It is customary for the host to insist that guests drink to show friendship. If the guest doesn't want a drink, the guest would say "I'm unable to drink, but thank you." Hosts' insistence is to show generosity. So refusal by the guests should be made with utmost politeness.

\subsection{Business Cards}

Nowadays, the use of business cards has become an indispensable way in social and business occasions. The first meeting will be given to business cards. A business card is the easiest way to introduce someone in a social situation. There are differences in the use of business cards between China and the United States. However, business cards are exchanged without formal ritual in America, and they are given at the beginning of a meeting. It is quite common for the recipient to put the card in their wallet, which may be in the back pocket of their trousers. Business cards are always carried.(Wang Ping, 2012) [6]. Husband and wife can use the same one. Domicile or place of work is in the right corner mostly, and the position is printed in central name under. A man may add Mr. to his name, and a married woman may add Mrs. In China, business cards are exchanged at the initial meeting. One side of the card is translated and printed the Chinese letters using gold ink as it is an auspicious color. The company, rank and any qualifications should be mentioned. When handing a card to the other side, you'd better smile and look at the other side. And both hands of the thumb and index finger respectively hold the two corners of the business card. If you are sitting, you should get up immediately when passing the card. It is impolite to leave the card lying around after you receive it. First, when you are meeting with a customer, it is best to read the important information on the card to show your respect. Whether in the orient or the west, knowing each other's business card etiquette in business communication is not only a formality, but also the culture and meaning behind it. Passing a business card is not just a small detail, and it can reflect people's quality and etiquette. A good impression can be left by the business exchange. At the same time, friction and embarrassment can be reduced in business activities, and cooperation can go smoothly.

\section{CONCLUSION}

In China, the value of life is often reflected in its social value. And the individual or self is always considered in the context of social relations. The Chinese pursue group harmony, and stable ethics nation. American culture is an individual culture in essence. Americans pay attention to science that they tend to be more rational in their approach. In fact, China is called "the country of etiquette". Advocating etiquette is the traditional virtue of Chinese people. From ancient times to now, the etiquette standard in China stands for Chinese unique civilization and the embodiment of Chinese virtues. Etiquette as a traditional virtue, has the heritage of history and eternal vitality. It can show the extent of enterprise civilization, management style and moral standards, shape the corporate image. Good manners will undoubtedly bring intuitive and direct benefits to the enterprise. There are some etiquettes in business work. In cross-cultural job, people should be able to handle the business etiquette of different cultures. Cross cultural business etiquette is a tool. It can teach people to learn ins and outs of global business. People often talk about how the world is getting "smaller" thanks to travel and technology. In fact, the reality is that, even though people in one country interact with different cultures more than ever. But there are still major differences. Everyone has 
different ideas, different ways of working, and different expectations. It makes life very amusing in a diverse world. Fundamentally speaking, commercial etiquette is the art of business man contact [4].

Based on the United States and China, this paper analyzes the differences in business etiquette between the two countries. Concept of time and giving gift as well as greeting etiquette and dressing etiquette of the United States and China are discussed and analyzed in depth. The purpose is to study Chinese and American business etiquette. Then it compared the two countries' business etiquette in the same field. Both sides have their own features and advantages. For instance, the Chinese dining rules, the Chinese usually like a pleasant atmosphere. But it's necessary to find out how to pick up your seat at the table. In America, Americans don't like lively atmosphere. Therefore, the characteristics of the two countries should be examined when conducting cross-cultural business activities [6].

Therefore, the author of this thesis has some suggestions for cross-cultural business activities:

Above all, it is necessary to respect each other's unique habitude. Cultural diversity is a fundamental feature of human society and an important driving force for the progress of human civilization. Respect for cultural diversity is essential for the development of national culture and global cultural prosperity. Only by maintaining cultural diversity will the world become more colourful and full of vitality. In commercial activities, respect the cultural characteristics of China and other parts of the world. Respect for national characteristics is both a sign of personal character and a way to promote cooperation. Therefore, it creates a perfect impression.

Secondly, deal with culture flexibly. In fact, through a certain amount of cross-cultural research, business people will become more interested in different cultures and improve their practice ability. A thorough understanding of different cultures is of great help in business work. Business people should understand and learn various business etiquette features. On this basis they need to formulate rational plan, select an expedient strategy, and develop all kinds of measures to prevent risks. Different countries have different business etiquette, which can cause some conflicts. It requires that business people should flexibly handle the problems. (Wang Ping, 2012) In fact, it is difficult to really master the differences in business culture. Therefore, business personnel should be flexible in the use of knowledge in business activities. It can help business people to solve the problems caused by cultural differences.
Therefore, business personnel in business activities should be flexible and initiative.

\section{AUTHORS' CONTRIBUTIONS}

This paper is independently completed by Tingting Xiao.

\section{REFERENCES}

[1] Brown Joanna. Good Business Etiquette Makes a Strong First Impression. [J]. CDS review, 2015,108(5).

[2] Hofstede, G. Culture's Consequences: Intercultural Differences in Work-Related Values [M]. Newbury Park, CA: Sage Publications, 1980.

[3] Michael Minkov. Cultures and Organizations: World Values Survey [M]. London: McGrawHill, 1991.

[4] Yang Ying. Cultural Differences Between China and West and Embodiment in Business Etiquette: A Cross-cultural Perspective [J]. Zhongnan University, 2009.

[5] Wang Huifang. Impact of Cultural Differences on Sino-American Business Communication [J]. Tianjin University of Finance \& Economics, 2010.

[6] Wang Ping. A Study on Difference of Business Etiquette Between China and the United States Based on Cultural Dimension Theory [D]. Xi'an Polytechnic University, 2012. 